\title{
WHISTLING IN THE DARK
}

The BDJ Upfront section includes editorials, letters, news, book reviews and interviews. Please direct your correspondence to the News Editor, Kate Quinlan at the BDJ, The Macmillan Building, 4 Crinan Street, London, N1 9XW or by email to BDJNews@nature.com

Press releases or articles may be edited, and should include a colour photograph if possible.

Peter Ward

Chief Executive BDA

$\mathrm{P}$ SA Report: '...in our view, neither the level of information actively provided to the Council in the paper on 20 February 2014 nor the level of scrutiny of the issues by the Council as recorded in the minutes were adequate in the circumstances...'

The stormy journey of the General Dental Council has now been impacted by the latest thunderbolt in the shape of a whopping 306 page report by the Professional Standards Authority (PSA) into allegations made by a whistle blower about the GDC's Fitness to Practise processes. The substance of the report is historic in that it relates to the way things were back in 2013. But the way those matters have been dealt with sits squarely with the current Council and most significantly its Chair.

The quote above, buried in the middle of the report, echoes what the BDA has been saying for over a year. It is the story of an executive management team failing to acknowledge, act upon or rectify its failings, and a governance body too ready to accept potted versions of the truth and make no further enquiries. While this may relate to a particular matter, it describes a course of conduct that is familiar in many aspects of the GDC's way of operating.

What is particularly alarming is the fact that even the body statutorily empowered to look over the GDC's shoulder has been denied full disclosure of what it needs to make a judgement on the case. The essence of the PSA's authority turns upon open disclosure (a 'duty of candour'?) on the part of the health and social care regulators. Sadly the GDC has chosen to make things difficult based upon its own assessment of what should and shouldn't be disclosed.

Disturbing as this attempt at legal

\section{1...the \\ General \\ Dental \\ Council \\ is truly \\ beyond \\ anyone's \\ control...'}

obfuscation is, at least it demonstrates that absolutely everyone is subject to the same approach by the GDC. Over the last 18 months, we have sought to obtain information, deliver comment and hold constructive dialogue with the GDC on a number of matters. In each instance we have been confronted by the same self-justifying avoidance of anyone else's view. Pseudo information and dogmatic arguments have been used to affirm the GDC's own take on things and suggest 'transparency'. This would be bad even if the organisation had a track record of high performance, but frankly it hasn't.

So after the last forays over the strategic plan and the ARF, BDA Chair Mick Armstrong wrote individually to each GDC Council member seeking reassurance that they had properly exercised their duties of enquiry and held the management to account. Disappointingly, but perhaps predictably, what came back was a single letter from the Chair responding on behalf of them all. As usual the response was incomplete and self-affurming. It reported exactly what we have seen in the PSA report - a Council that neither questions nor challenges and which instead relies on what the executive tells it to believe.

So this whole set of circumstances throws up a series of important questions. Here is a body that is funded by a profession to oversee it. Unarguably, the organisation is not very good at some fundamental areas of its role and is unprepared to recognise its own failings. Wherever possible it blames outside issues (legislation, the profession, truculent individuals) for its own weaknesses. It steadfastly avoids attributing any of the failure to its own people, some of whom have demonstrably been central to the problem.
The management has sought continuously to 'news manage' the internal story and the governing Council has swallowed that self-preserving version without much question. The Chair's role in this series of misrepresentations must be open to question. And then when the one remaining potential inquisitor has sought to investigate, the organisation has blocked its way.

The summary is, then, that the GDC is truly beyond anyone's control. And whistle blowers beware here! You will be named, shamed and disparaged and, notwithstanding supposed protection, this organisation will fight every inch of the way to avoid accountability.

Late last year, and before the publication of this report, the BDA wrote two letters to senior figures in government and parliament. We wrote expressing grave concerns about the GDC's approach to consultation, its management and the lack of any meaningful governance. We wrote to question whether the current Chair of the GDC was the right person to lead the appointment of the next Chief Executive. The publication of this report underlines and validates those concerns. We have still received no response from Westminster and the GDC itself has been noticeably silent in the face of this damning indictment - at the time of writing in early January 2016, no reference to the report was visible on its website. It is imperative that the dental profession receives some answers. And they need to be good ones.

We want a GDC. We want a GDC that is properly governed, properly managed and proportionate in its undertakings. Maybe this report can be the catalyst for change that will at last, allow us to have one.

DOI: 10.1038/sj.bdj.2016.1 